\title{
Japan's research spending rises again
}

[TOKYO] Despite a struggling economy, overall research spending in Japan grew by 3.4 per cent in the fiscal year 1996 (which ended in March 1997), according to a survey on research and development (R\&D) expenditure by the Management and Coordination Agency, a government agency that reports to the prime minister's office.

The survey, based on data provided by several thousand companies, universities and research institutes, estimates total $R \& D$ spending at $¥ 14.9$ trillion (US\$ 115 billion). If the software industry - included for the first time in this year's survey — is added, this figure rises to $¥ 15.1$ trillion.

Although this year's increase is below last year's rise of 6 per cent, it is still considerably more than the growth in gross domestic product (GDP). With an estimated 3 per cent of total GDP spent on research during 1996, Japan remains well ahead of all the other large industrialized countries, whose growth rates have been below those of GDP for much of the past decade.

But although industrial R\&D - excluding software - displayed a record 5.2 per cent increase, that for higher education is estimated at a modest 1 per cent. Indeed, although spending appears to have increased markedly in private universities, public funding for university research actually declined by several percentage points. Funding at research institutes - which includes both public and private institutions - also went down, by 1.1 per cent.

Furthermore, overall public research spending decreased by some 4 per cent, according to the survey, a figure that appears to conflict with the large nominal increases in long-term government research funding budgeted for the same period (see Nature $385,104 ; 1997)$. This discrepancy is partly explained by unusually generous 'supplementary budgets' for the previous year, which added considerably to a 12 per cent increase in public research spending.

As part of a $¥ 14$ trillion government effort to stimulate the economy, supplementary budgets in 1995 included an additional $¥ 685$ billion for research. Most of this, however,

\section{Inquiry looks into Indian cancer deaths}

[NEW DELHI] An inquiry is being set up to investigate allegations that medical treatment was deliberately withheld from 1,107 Indian women with uterine cervical dysplasias, even though it was known that some of the lesions could become cancerous. The seven-member inquiry committee will be headed by a retired judge.

The women, who were attending gynaecology wards in six hospitals, were part of a study on cervical cancer, but had not given written consent to take part in the experiment. Rather than being treated, they were registered for a long-term follow-up, during which 69 women 'progressed to malignancy' and had to undergo cancer treatment or have the uterus removed. Two women died during radiation treatment. Investigators do not know what happened to ten others with advanced dysplasias who failed to report for the follow-up.

The study, conducted between 1976 and 1988 by the Indian Council of Medical Research (ICMR), was intended to identify risk factors in the transformation of dysplasias into cervical cancer, the biggest killer among cancers in Indian women.

Usha Luthra, ICMR's then deputy chief and the project's principal investigator, maintains that the women were "verbally" informed, as written consent was not mandatory at the time. "Ethical guidelines keep changing. If I had to go back to the 1970 s I would repeat the study exactly the same way," she says. She says the study helped India to evolve screening guidelines for a national cancer control programme.

But some doctors and women's groups are questioning the ethics of the study in the absence of documented proof that the women - mostly poor and illiterate - were made aware that their lesions could develop into cancer without treatment. Saheli, a prominent women's group, has appealed to the National Human Rights Organization for "stringent actions against those responsible for the barbaric tests".

Vulimuri Ramalingaswami, who headed ICMR between 1978 and 1985, argues that the study should be viewed in the context of the ethical standards of the time (the ICMR had no guidelines until 1980). "When it was found that moderate and severe dysplasias more often turned into cancer, such women were taken off the study and put on treatment," he says.

But N. P. Gupta, formerly deputy director general of ICMR, describes the study as inhuman. "I did not know that such a study was going on. We are all criminals." G. V. Satyavati, the immediate past head of ICMR, ordered a probe by an independent committee before she retired in August.

Although the controversial study was closed nine years ago, it is being highlighted now to ensure that ICMR's guidelines which are being revised by a committee headed by the former chief justice of the supreme Court — are made tougher than those issued in 1980.
K.S. Jayaraman

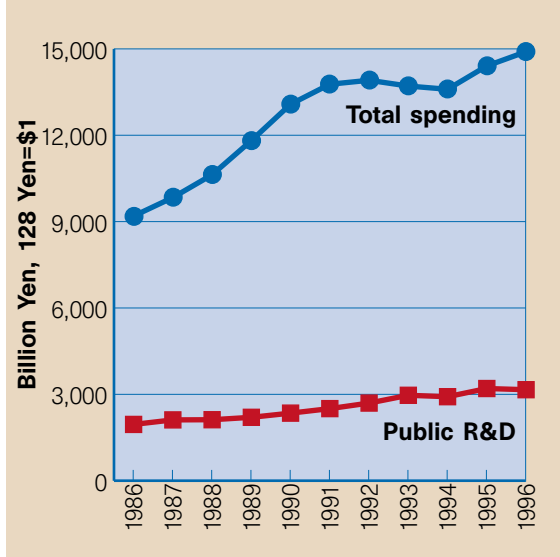

Onward and upward: R\&D expenditures have shaken off the recession of the early 1990s.

went into new buildings and facilities for universities and national institutes; extra funds for R\&D in last year's supplementary budgets amounted to only $¥ 155$ billion.

The large increase in private expenditures revealed by this year's survey appears to confirm claims that the political objective of the 'Basic Law' was aimed less at raising public research spending than at reinvigorating private-sector $\mathrm{R} \& \mathrm{D}$. After periods of sustained growth during the 1980s, companies had been cutting their research budgets in the early 1990s because of the recession.

But since last year, industrial $\mathrm{R} \& \mathrm{D}$ has been rising again. This trend appears to be confirmed by a recent survey of some 200 large corporations by the Nikkan Kogyo Shimbun, a daily newspaper for business and technology, which found growth rates for 1997 of between 2 and 10 per cent for all industries except petroleum refining. Growth in industrial R\&D has been most marked in the electronics, telecommunications and transport sectors. Total R\&D in software was estimated at only $¥ 177$ billion, a sum that is below R\&D spending by some individual US companies.

According to Shinichi Kobayashi, a science policy analyst at the University for Electro-Communications near Tokyo, R\&D expenditure in small and medium-sized enterprises is inadequately measured, and as a result the data provided by the survey may underestimate structural changes in the Japanese economy.

In particular, analysis of inter-company $\mathrm{R} \& \mathrm{D}$ funding, as measured by the annual survey, reveals a widening gap between the total amount received by industry and that paid out for research, leaving a growing proportion of funds spent on extramural R\&D unaccounted for. According to Kobayashi, this suggests a trend towards out-sourcing of $\mathrm{R} \& \mathrm{D}$ to small companies that does not show up in the survey data.

RobertTriendl 